\title{
Erratum to: Advances in Machine Vision Applications for Automatic Inspection and Quality Evaluation of Fruits and Vegetables
}

Sergio Cubero $\cdot$ Nuria Aleixos $\cdot$ Enrique Moltó $\cdot$

Juan Gómez-Sanchis • Jose Blasco

Published online: 28 April 2011

(C) Springer Science+Business Media, LLC 2011

Erratum to: Food Bioprocess Technol (2011) 4:487-504

DOI 10.1007/s11947-010-0411-8

The original version of this article unfortunately contained a mistake. The Fig. 4 image was incorrect in the PDF while the image in the HTML is correct. The correct figure is given below.

The online version of the original article can be found at http://dx.doi. org/10.1007/s11947-010-0411-8.

S. Cubero $\cdot$ E. Moltó $\cdot$ J. Blasco $(\bowtie)$

Centro de Agroingeniería, Instituto Valenciano de Investigaciones,

Agrarias,

Cra. Moncada-Náquera, Km. 5,

46113 Moncada, Spain

e-mail: blasco_josiva@gva.es

S. Cubero

e-mail: cubero_ser@gva.es

E. Moltó

e-mail: molto_enr@gva.es

N. Aleixos

Instituto Interuniversitario de Investigación en

Bioingeniería y Tecnología Orientada al Ser Humano,

Universidad Politécnica de Valencia,

Camino de Vera $\mathrm{s} / \mathrm{n}$,

46022 Valencia, Spain

e-mail: naleixos@dig.upv.es

J. Gómez-Sanchis

Intelligent Data Analysis Laboratory (IDAL), Electronic

Engineering Department, Universitat de València,

Dr. Moliner 50,

46100 Burjassot (Valencia), Spain 


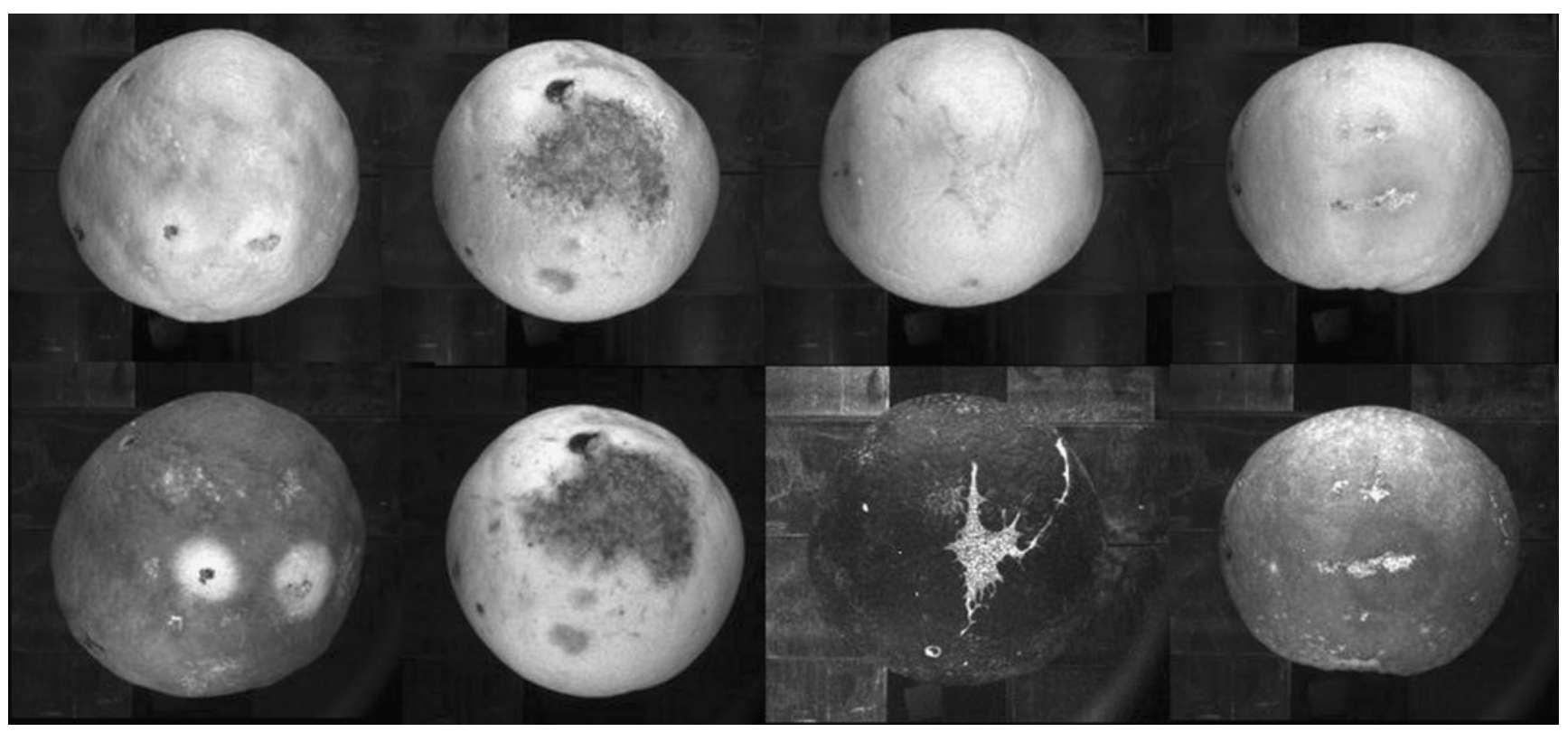

Fig. 4 Images of citrus fruits with different external defects acquired with a B/W monochromatic camera (top) and the same fruit acquired at a particular wavelengths (bottom). From left to right: 450, 720, 520 and $480 \mathrm{~nm}$ 